Thorax 1985;40:101-106

\title{
Haemodialysis and haemofiltration on cardiopulmonary bypass
}

\author{
M HAKIM, D WHEELDON, DW BETHUNE, BB MILSTEIN, TAH ENGLISH, \\ J WALLWORK
}

Department of Cardiothoracic Surgery, Papworth Hospital, Papworth Everard, Cambridge

\begin{abstract}
Over a three year period we have used haemodialysis and haemofiltration in parallel with cardiopulmonary bypass in 26 patients. Impaired renal function and excessive fluid retention have been the main indications. Patients on haemodialysis programmes for end stage renal failure did not require further dialysis until at least the third postoperative day, when they could tolerate the haemodynamic disturbance of dialysis. In the other patients these techniques proved valuable in reversing the effects of haemodilution and in controlling the concentration of serum potassium. Our experience has confirmed that haemodialysis and haemofiltration in parallel with cardiopulmonary bypass are useful adjuncts in the perioperative management of patients with impaired renal function undergoing open heart surgery. The techniques are also effective in correcting the fluid retention and biochemical imbalance in patients with congestive cardiac failure, including those with heart transplants.
\end{abstract}

Haemodialysis and haemofiltration on cardiopulmonary bypass are relatively new techniques. Haemodialysis during cardiopulmonary bypass was first described by Soffer et al in $1979 .{ }^{1}$ The process requires a dialysate solution and depends on the concentration gradient of solutes across the dialyser membrane. The technique of haemofiltration during cardiopulmonary bypass, first instituted by Darup et al in $1979,{ }^{2}$ does not require the flow of a dialysate fluid with its inherent complexities. The driving force for haemofiltration is the pressure gradient across the membrane rather than a concentration gradient as in dialysis.

The transmembrane pressure is determined by the positive pressure applied to the blood and the negative pressure applied to the other side of the membrane. The blood flow through the filter is a function of pressure in the arterial line of the bypass circuit and the resistance of the haemofiltration circuit. A blood flow of $300-500 \mathrm{ml} / \mathrm{min}$ through the filter device and a transmembrane pressure of about 300 $\mathrm{mm} \mathrm{Hg}$ are considered safe and will not cause appreciable haemolysis.

Address for reprint requests: Mr M Hakim, Department of Cardiothoracic Surgery, Papworth Hospital, Papworth Everard, Cambridge, England.

Accepted 1 October 1984
These techniques represent a major improvement in the perioperative care of patients with impaired renal function undergoing open heart surgery. In addition to restoring normovolaemia and a normal packed cell volume at the end of the operation, intraoperative dialysis and haemofiltration provide a satisfactory means of controlling the serum potassium concentration.

\section{Patients and methods}

From January 1981 to December 1983 haemodialysis and haemofiltration were used during cardiopulmonary bypass in 26 patients $(20$ men, six women). The mean age was 56 (range 18-72) years. The indications for the use of these techniques are shown in table 1 . The surgical procedures included eight valve replacements, three myocardial revascularisations, three combined procedures, and seven orthotopic heart transplantations (table 2).

Five patients received dialysis during the perfusion period. Dialysis was carried out with a Nephros Allegro dialyser (Organon Teknika-Veedijk 582300, Turnhont, Belgium), against 10-20 litres of Boots $1.36 \%$ dialysate solution (Boots Hospital Products, Boots Company PLC, Nottingham), with additional potassium as necessary. Blood was supplied to the dialyser at a flow rate of $200-300 \mathrm{ml} /$ min, via a shunt in the bypass circuit. The dialysate 
Table 1 Indications for dialysis or haemofiltration during cardiopulmonary bypass (CPB)

\begin{tabular}{ll}
\hline Indication & No of patients \\
\hline Chronic endstage renal failure & \\
$\quad$ (regular haemodialysis) & 5 \\
Secondary renal impairment (blood urea & \\
$\quad>10$ mmol/l) & 16 \\
Fluid retention due to cardiac failure & 4 \\
Excessive haemodilution during CPB & 1 \\
\hline
\end{tabular}

Conversion: SI to traditional units-Blood urea: $1 \mathrm{mmol} / \mathrm{l}=6.024$ $\mathrm{mg} / 100 \mathrm{ml}$.

circuit consisted of a roller pump circulating fluid from a 10 litre container through the dialyser, while maintaining negative pressure, at a flow rate of 2 litres per minute.

The subsequent 21 patients had haemofiltration in parallel with cardiopulmonary bypass. The filters used were the hollow fibre type-Gambro FH202 (Gambro, PO Box 10101, S-202010 Lund, Sweden) and Dylade D6 (Dylade Co Ltd, Astmoor Industrial Estate, Runcorn, Cheshire). Blood flow through the filter was maintained at $300-500 \mathrm{ml} / \mathrm{min}$ (about $10 \%$ of the pump output). A transmembrane pressure of about $300 \mathrm{~mm} \mathrm{Hg}$ was maintained.

When haemofiltration was used purely for correction of fluid retention due to cardiac failure, or to correct excessive haemodilution, it was instituted towards the final stages of the perfusion. When haemofiltration was used to clear metabolites, however, it was carried out during the entire bypass period with volume replacement by Hartmann's solution, to each litre of which was added $30 \mathrm{mmol}$ sodium bicarbonate. Figure 1 illustrates the haemofiltration circuit during bypass.
Table 2 Patients who received parallel haemofiltration or haemodialysis from 1981 to 1983

\begin{tabular}{ll}
\hline Operation & No of patients \\
\hline Coronary artery bypass grafting (CABG) & 3 \\
Aortic valve replacement (AVR) & 5 \\
Mitral valve replacement (MVR) & 1 \\
AVR and MVR & 2 \\
MVR and CABG & 2 \\
AVR, MVR, and CABG & 1 \\
Orthotopic heart transplantation & 7 \\
Repair of postinfarction ventricular & 1 \\
septal defect & 1 \\
Repair of mitral paraprosthetic leak & 1 \\
Left ventricular aneurysmectomy & 1 \\
Right atrial to pulmonary artery conduit & 1 \\
Closure of aortic to right ventricular fistula & 1 \\
\hline
\end{tabular}

\section{Results}

PATIENTS WITH ESTABLISHED ENDSTAGE RENAL FAILURE

All five patients with established endstage renal failure (table 3) were having regular haemodialysis. The mean serum potassium concentration immediately after operation was $4.5 \mathrm{mmol}(\mathrm{mEq}) / \mathrm{l}$. In three patients the serum potassium concentration started to rise within 24 hours of operation. Intermittent doses of $50 \%$ dextrose and insulin with calcium resonium successfully controlled the serum potassium. Excessive fluid retention and rapid rise of blood urea were not encountered in the immediate postoperative period and the patients did not require further dialysis until the third or fourth postoperative day, when they were in a more stable haemodynamic state and could tolerate haemodialysis. The mean blood urea concentration 24 hours after operation was $24.3 \mathrm{mmol} / \mathrm{l}(146.4$

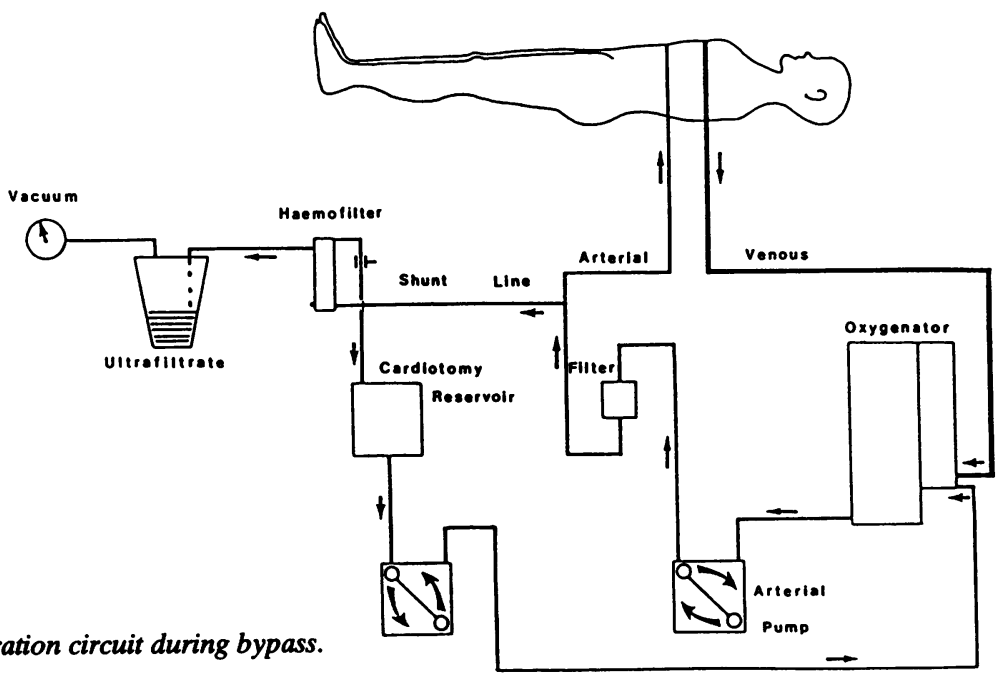

Fig 1 Haemofiltration circuit during bypass. 
Table 3 Patients with endstage renal failure who had haemodialysis or haemofiltration during cardiopulmonary bypass

\begin{tabular}{|c|c|c|c|c|c|c|}
\hline \multicolumn{2}{|c|}{ Urea (mmol/l) } & \multicolumn{2}{|c|}{ Potassium (mmol/l) } & \multirow{2}{*}{$\begin{array}{l}\text { Pump prime } \\
\text { and additions } \\
\text { (ml) }\end{array}$} & \multirow{2}{*}{$\begin{array}{l}\text { Fluid } \\
\text { removed }(\mathrm{ml})\end{array}$} & \multirow[t]{2}{*}{ Technique } \\
\hline $\begin{array}{l}\text { Before } \\
\text { operation }\end{array}$ & After & $\begin{array}{l}\text { Before } \\
\text { operation }\end{array}$ & After & & & \\
\hline $33 \cdot 0$ & 29.4 & $5 \cdot 4$ & $4 \cdot 6$ & 2400 & 2200 & \multirow{3}{*}{$\begin{array}{l}\text { Dialysis against } 201 \text { Boots } \\
\text { solution } 1 \cdot 36 \% \text { and } 35 \mathrm{mmol} \mathrm{k}^{+} / \mathrm{l} \\
\text { Dialysis against } 201 \text { Boots } \\
\text { solution } 1 \cdot 36 \% \\
\text { Haemofiltration (FH202) } \\
\text { Haemofiltration (D6) } \\
\text { Haemofiltration (D6) }\end{array}$} \\
\hline $34 \cdot 0$ & $23 \cdot 1$ & $4 \cdot 0$ & $4 \cdot 5$ & 1500 & 600 & \\
\hline $\begin{array}{l}28 \cdot 7 \\
47 \cdot 5 \\
15 \cdot 0\end{array}$ & $\begin{array}{l}22 \cdot 0 \\
36 \cdot 5 \\
10 \cdot 5\end{array}$ & $\begin{array}{l}4 \cdot 3 \\
4 \cdot 8 \\
4 \cdot 3\end{array}$ & $\begin{array}{l}4 \cdot 8 \\
4 \cdot 1 \\
4 \cdot 5\end{array}$ & $\begin{array}{r}15350 \\
20000 \\
5800\end{array}$ & $\begin{array}{r}15200 \\
19050 \\
4800\end{array}$ & \\
\hline
\end{tabular}

D6-Dylade D6 haemofilter; FH202-Gambro FH202 haemofilter.

Conversion: SI to traditional units-Blood urea: $1 \mathrm{mmol} / \mathrm{l}=6.024 \mathrm{mg} / 100 \mathrm{ml}$; potassium: $1 \mathrm{mmol} / \mathrm{l}=1 \mathrm{mEq} / \mathrm{l}$.

$\mathrm{mg} / 100 \mathrm{ml}$ ) (mean preoperative concentration 31.6 $\mathrm{mmol} / \mathrm{l}(190.4 \mathrm{mg} / 100 \mathrm{ml}))$.

\section{PATIENTS WITH SECONDARY RENAL \\ IMPAIRMENT}

Secondary renal impairment, which was present in 16 cases, was defined arbitrarily as a blood urea concentration higher than $10 \mathrm{mmol} / \mathrm{l}$. Dialysis was used in three patients, where the mean volume of fluid removed was $2160 \mathrm{ml}$ (mean volume of pump prime and additions $2360 \mathrm{ml}$ ). Haemofiltration was used in 13 patients. The mean volume of ultrafiltrate was $6860 \mathrm{ml}$ (mean volume of pump prime, additions and replacement $7800 \mathrm{ml}$ ). The postoperative serum potassium concentration ranged from 3.5 to 5.1 (mean 4.4 ) mmol/l (mean preoperative concentration $4.3 \mathrm{mmol} / \mathrm{l})$. The mean postoperative urea concentration was $13.4 \mathrm{mmol} / \mathrm{l}(80.7 \mathrm{mg} / 100 \mathrm{ml})$ (mean preoperative concentration $16.4 \mathrm{mmol} / 1(98.8 \mathrm{mg} /$ $100 \mathrm{ml})$ ). Figure 2 shows the perioperative changes in blood urea. There was a rise in blood urea concentration in two patients 24 hours after operation. One of these received a dose of cyclosporin A (a known nephrotoxic drug) before an aborted heart transplantation. Twenty-four hours later he received a second dose of cyclosporin $\mathrm{A}$ and heart transplantation was carried out. The second patient, who had multiple congenital defects, was anuric with a steadily rising urea concentration for 24 hours before operation.

There were two deaths in this group. One patient, who had had an aortic and mitral valve replacement, returned to the intensive care unit with full inotropic support and balloon counterpulsation. Renal function showed temporary improvement but the patient developed systemic septicaemia and respiratory failure and died four weeks later. The second patient, with multiple congenital defects and hypoplastic right ventricle, died on the second postoperative day from low cardiac output.

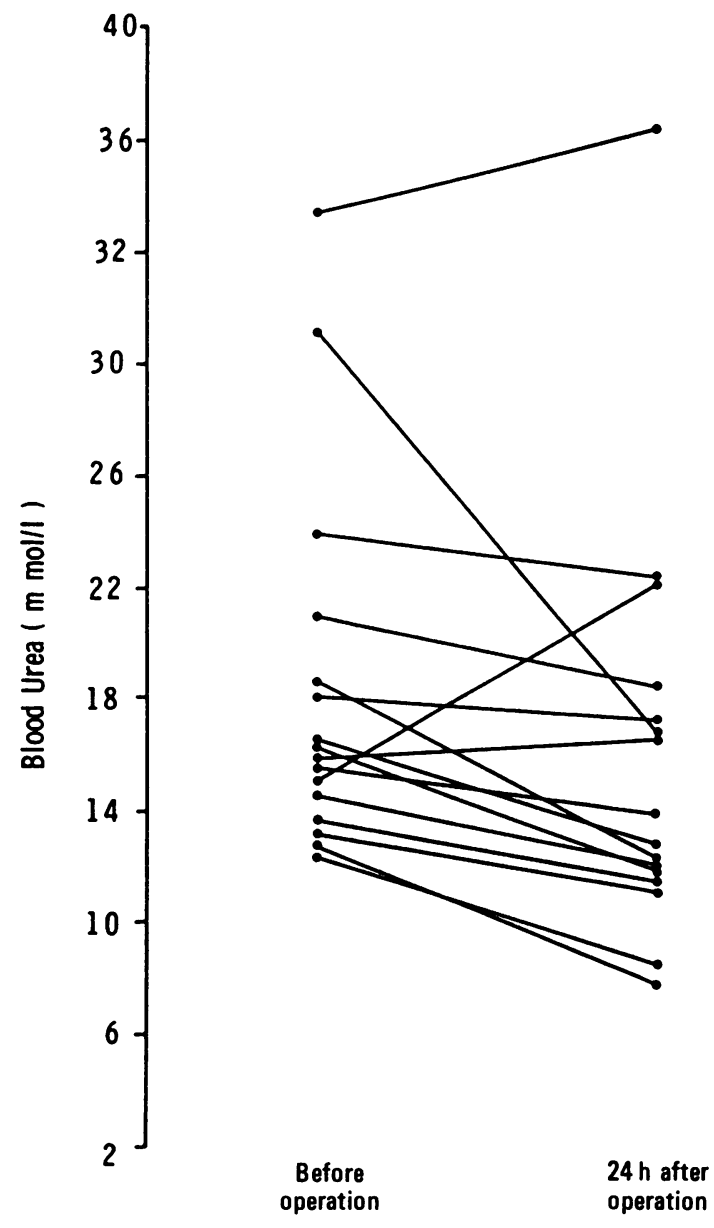

Fig 2 Perioperative changes in blood urea in patients with secondary renal impairment who received dialysis or haemofiltration during cardiopulmonary bypass. 
Table 4 Patients with fuid retention secondary to congestive cardiac failure who received parallel haemofiltration

\begin{tabular}{lll}
\hline $\begin{array}{l}\text { Pump prime and } \\
\text { additions }(m l)\end{array}$ & $\begin{array}{l}\text { Ultrafiltrate } \\
\text { volume }(\mathrm{ml})\end{array}$ & Technique \\
\hline 1750 & 1400 & Haemofiltration (FH202) \\
2900 & 2100 & Haemofiltration (D6) \\
1650 & 3400 & Haemofiltration (FH202) \\
1500 & 2000 & Haemofiltration (D6) \\
\hline
\end{tabular}

PATIENTS WITH FLUID RETENTION SECONDARY TO CONGESTIVE CARDIAC FAILURE

In the four patients with fluid retention secondary to congestive cardiac failure (table 4) the mean blood urea was slightly raised at $7 \cdot 2$ (range 4.1-9.0) $\mathrm{mmol} / \mathrm{l}$ (43.3 (range 24.7-54.2) $\mathrm{mg} / 100 \mathrm{ml}$ ). Haemofiltration, however, was carried out only to correct the pre-existing fluid retention and the haemodilution imparted to the patient as a result of cardiopulmonary bypass. All patients had haemofiltration for 10-20 minutes towards the end of the perfusion period. The mean volume of ultrafiltrate was $2225 \mathrm{ml}$ (mean volume of pump prime and additions $1850 \mathrm{ml}$ ).

\section{Discussion}

Although renal dysfunction secondary to cardiopulmonary bypass is now a relatively uncommon complication, ${ }^{34}$ a steadily increasing number of patients with pre-existing renal disease are presenting for open heart surgery. ${ }^{5-8}$ In addition, the recognition of surgically correctable complications of myocardial infarction and the tendency towards early surgery in the management of infective endocarditis present cardiac surgeons with a group of patients with low cardiac output and impaired renal function.

After open heart surgery in patients with normal renal function, the kidneys can eliminate the excess water load which follows the haemodilution in the extracorporeal circuit. Although diuresis is the most physiological method of haemoconcentration, it is not always as effective as desired because of low cardiac output or pre-existing renal dysfunction.

Mechanical washing and concentration of the red cells with a cell saver is an effective method of haemoconcentration. This technique, however, is a discontinuous method which requires batch processing of the blood. Plasma is lost and the cost of capital and disposable equipment is high. ${ }^{9}$

Haemofiltration in parallel with cardiopulmonary bypass, on the other hand, is a simple and effective procedure, which provides the perfusionist with an additional tool to accomplish haemoconcentration. Haemofiltration can be achieved with either purpose designed haemofilters, which tend to be expensive, or high flux dialysers, some of which are almost as efficient at haemofiltration as the purpose designed filters but much cheaper. The limiting factor for the removal of ultrafiltrate during haemofiltration is the membrane pore size and geometry and the surface area. All solutes with a molecular size less than the pore size of the membrane are filtered and those with a larger molecular size are retained (fig 3 ). Figure 4 illustrates the clearance rates of various dialysers and haemofilters. By removal of excess fluid normovolaemia and a normal packed cell volume can be restored. Furthermore, plasma protein concentration and plasma osmotic pressure, which are known to be reduced during bypass, ${ }^{10}$ can be

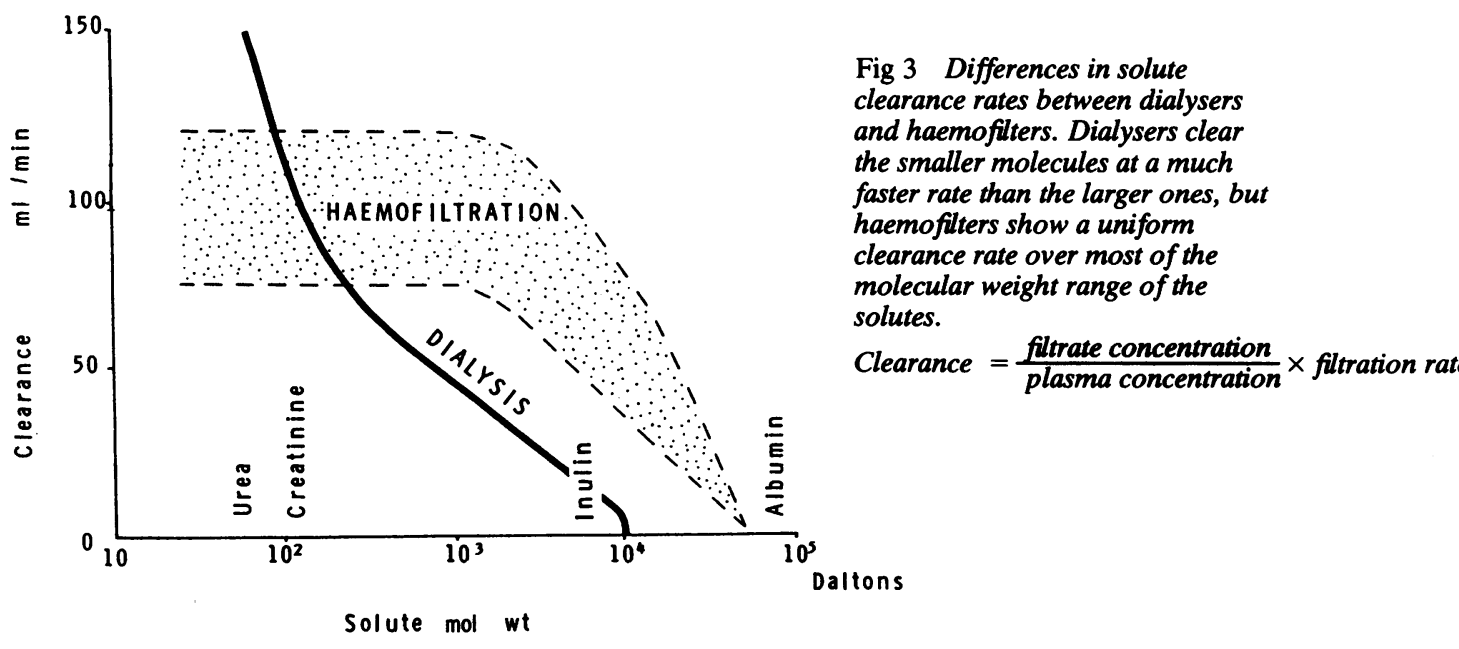




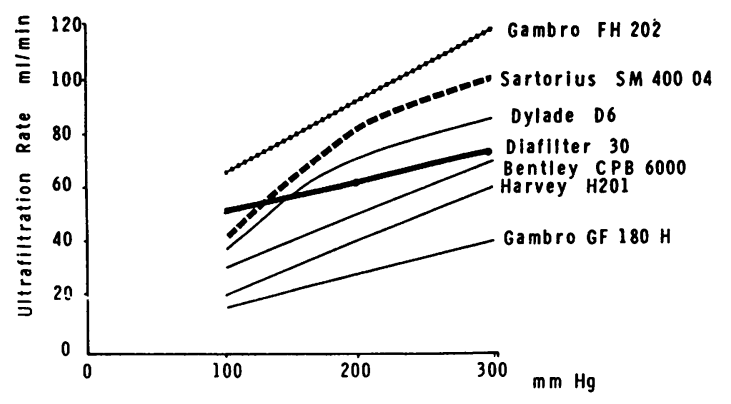

Transmembrane pressure

Fig 4 Relative performances of the dialysers and haemofilters with respect to ultrafiltration rates at various transmembrane pressures. Blood flow is $300 \mathrm{ml} / \mathrm{min}$, packed cell volume $0 \cdot 25$, and temperature $37^{\circ} \mathrm{C}$. The FH202, SM 40004, and Diafilter 30 are pure haemofilters while the others are high fux dialysers. The Diafilter 30 performs well at lower transmembrane pressures, making it suitable for use without vacuum.

restored to preoperative levels. This promotes absorption of interstitial fluids ${ }^{11}$ and helps to prevent clinically important as well as subclinical pulmonary oedema in the early postoperative period. ${ }^{12}$

As the ultrafiltration rate can be up to $40 \%$ of the blood flow through the filter, haemofiltration provides an efficient method for haemoconcentration. In fact, the pump prime and fluid additions during bypass (1.5-3 litres) can be removed in the last 10-15 minutes of perfusion.

When haemofiltration is also used to clear metabolites the procedure can be carried out during the entire bypass by means of volume replacement. We have used Hartmann's solution with the addition of $30 \mathrm{mmol}$ sodium bicarbonate per litre, although one of the standard haemofiltration replacement solutions (table 5) could be used instead. Haemofiltration in addition provides an excellent means for the control of serum potassium in patients with imparied renal function, and allows unlimited use of potassium containing cardioplegic solutions if desired.

A major point of concern when haemofilters were first used was the possibility of damage to blood elements. Ivanovich et al, from studies on haemofiltration for renal failure, found no appreciable rise is plasma free haemoglobin in either the ultrafiltrate or the plasma. ${ }^{13}$ This has been confirmed with the use of haemofiltration during cardiopulmonary bypass. ${ }^{14}$ It has also been shown that the platelet count after bypass is not significantly different from that in the non-haemofiltration group. ${ }^{14}$

Keshawiah et al have reported slight metabolic acidosis when haemofiltration was used for more than one or two hours (paper to seventh annual meeting of clinical dialysis and transplant forum of National Kidney Foundation, 1977). Preferential movement of anions-related to the rise in plasma protein concentration-was suggested as causing depletion of plasma bicarbonate. Frequent monitoring of acid-base balance and bicarbonate replacement if necessary have overcome this problem.

An additional point requiring consideration is the possible clearance of heparin by the haemofilter. ${ }^{15}$ Frequent measurements of the activated clotting time were therefore made during the period of haemofiltration, but we found little requirement for additional heparin even in those patients where more than 15 litres of ultrafiltrate were removed during the bypass period.

In conclusion, our initial experience with the use of heamofiltration in parallel with cardiopulmonary bypass has confirmed that this technique adds a new dimension to the perioperative management of patients with impaired renal function or with excessive fluid retention.

We would like to acknowledge the help of $\mathrm{Mr} \mathrm{R}$ Cory-Pearce, FRCS, and the excellent secreterial work of Mrs P Norman.

\section{References}

1 Soffer O, McDowell RC, Finlayson DC, et al. Intraoperative haemodialysis during cardiopulmonary bypass in chronic renal failure. $J$ Thorac Cardiovasc Surg 1979;77: 789-91.

2 Darup J, Bleese N, Kalmer P, Lute G, Pokar A, Polonius MJ. Haemofiltration during extracorporeal circulation. Thorac Cardiovasc Surg 1979;27:227-30.

3 Bethune DW. Organ damage after open heart surgery. Lancet 1976;ii:1410-1.

4 Bethune DW. Organ damage following open heart

Table 5 Composition of the haemofiltration solutions used

\begin{tabular}{lllllllll}
\hline Solution & $\mathrm{Na}$ & $\mathrm{K}$ & $\mathrm{Ca}$ & $\mathrm{Mg}$ & $\mathrm{Cl}$ & Lactate & Acetate & Glucose \\
\hline Gambro HF-1 & 140 & $1 \cdot 0$ & $3 \cdot 25$ & $1 \cdot 5$ & $100 \cdot 1$ & 45 & $2 \cdot 154$ \\
Gambro HF-4 & 135 & $3 \cdot 0$ & $3 \cdot 75$ & $1 \cdot 5$ & $109 \cdot 5$ & 34 & 35 & $1 \cdot 65$ \\
Gambro HF-5 & 140 & & $4 \cdot 0$ & $2 \cdot 0$ & 111 & & \\
Boots & 143 & $3 \cdot 0$ & $1 \cdot 88$ & $1 \cdot 0$ & 118 & 34 & \\
Hartmann's Solution & 131 & $5 \cdot 0$ & $2 \cdot 0$ & & 111 & 29 & \\
\hline
\end{tabular}


surgery. Proceedings of First World Congress on Open Heart Technology. London: Franklin Scientific, 1982:123-7.

5 Chawla R, Gailianus P jun, Lazarus JM, et al. Cardiopulmonary bypass surgery in chronic haemodialysis and transplant patients. Trans Am Soc Artif Intern Organs 1977; 23:694-6.

6 Crawford FA jun, Selby JH, Bower JD, Lehan PH. Coronary revascularisation in patients maintained on chronic haemodialysis. Circulation 1977; 56:684-7.

7 Lansing AM, Leb DE, Berman LB. Cardiovascular surgery in end-stage renal failure. JAMA 1968; 204:682-6.

8 Lavelle KJ, Dentino MM. Surgical treatment of infective endocarditis in haemodialysis patients. Clin Neph 1978;9:6-10.

9 Brickley JM, Kalshoven JD, Wilds SL, Dearing JP. A comparison of two methods of post-bypass haemoconcentration. Journal of Extracorporeal Technology $1982 ; 14: 431-6$.
10 English TAH, Digerness S, Kirklin JK. Changes in colloid osmotic pressure during and shortly after open intracardiac operation. J Thorac Cardiovasc Surg 1971;61:338-41.

11 Ing TS, Vilbar RM, Shin KD, et al. Predialytic isolated ultrafiltration. Dial Transplant 1978;7:557-9.

12 Klancke KA, Assey ME, Kratz JM, Crawford FA. Postoperative pulmonary oedema in post coronary artery bypass graft patients. Chest 1983;84:529-34.

13 Ivanovich P, Huang C, Stefanowich N. Haemofiltration: a useful adjunct to dialysis. Proc Eur Dial Transplant Assoc 1977; 14:605.

14 Hopeck JM, Lane RS, Schroeder JW. Oxygenator volume control by parallel ultrafiltration to remove plasma water. Journal of Extracorporeal Technology 1981;13:267-71.

15 Holt DW, Landis GH, Dumond DA, Hardin SB, Miller M. Haemofiltration as an adjunct to cardiopulmonary bypass for total oxygenator volume control. Journal of Extracorporeal Technology 1982;14:373-7. 